\title{
Efficiency Analysis of Mongolian Commercial Banks Based on DEA Malmquist Index
}

\author{
Zhihui Liu \\ School of Economics and Management \\ Inner Mongolia University \\ Hohhot, People's Republic of China \\ 1018859449@qq.com
}

Siqin

School of Mathematical Sciences Inner Mongolia University

Hohhot, People's Republic of China siqin12138@163.com

\author{
Zhanxin Ma* \\ School of Economics and Management \\ Inner Mongolia University \\ Hohhot, People's Republic of China \\ em_mazhanxin@imu.edu.cn \\ Otgontsetseg \\ School of Economics and Management \\ Inner Mongolia University \\ Hohhot, People's Republic of China \\ 3535240294@qq.com
}

\begin{abstract}
Commercial banks play an important role in the Mongolian financial system. Although Mongolian commercial banks have shown great development in the past two years, the low efficiency of the banking industry is still a problem that has plagued Mongolia's financial industry in a period of time. Therefore, improving the efficiency of commercial banks is the key to the sustainable development of Mongolia's financial industry problem. In order to analyze the operational efficiency of Mongolian commercial banks, this paper is based on the DEA-Malmquist index analysis method for the first time to study the total factor productivity of 13 Mongolian commercial banks in 2013-2017. The results show that: (1) the total factor productivity of Mongolian commercial banks is generally on the rise; (2) the changes in pure efficiency and pure technology are generally on the rise; (3) the changes in the scale factors of Mongolian commercial banks show two trends.
\end{abstract}

Keywords-Multi-objective planning; comprehensive evaluation;total factor productivity; DEA-Malmquist index; Mongolian commercial bank.

\section{INTRODUCTION}

As a fast-growing economic system of Mongolia, Mongolian Commercial Bank has attracted the attention of many researchers, but most researchers pay more attention to the risk prediction and supervision of commercial banks. There are few related studies on the efficiency analysis of commercial banks, and the efficiency of commercial bank plays a very important role in the economic development of the financial industry and even the country.

Since the 20th century, the field of bank efficiency research has attracted the interest of Mongolian economists and scholars, and many studies have appeared. For example, reference [1] first applied the data envelopment analysis method to analyze the economic benefits of Mongolian wheat production. Reference [2] explored the credit risk efficiency of the banking industry from 2002 to 2006 and studied the influencing factors of credit risk in the banking industry. Reference [3] analyzed

National Natural Science Foundation of China (71661025, 71261017); Inner Mongolia Natural Science Foundation (2016MS0705); Inner Mongolia Grassland Talent Project (12000-12102012); Inner Mongolia University Independent Research Project (20700-5187023) the operational efficiency of commercial banks between 2006 and 2010 and found that banking competition and banking efficiency are closely related. Reference [4] analyzed the operating efficiency of commercial banks based on the financial statements of 15 commercial banks from 2004 to 2010. The results show that the operating costs of the banking system are relatively low.

However, financial indicators or the weighted average of these indicators cannot fully reflect the bank's operating efficiency. Data Envelopment Analysis (DEA) is an important method for evaluating the relative effectiveness of decision-making units in the current stage of solving multi-input and multi-output problems. It is possible to obtain improved methods of decision-making units through projection analysis in the case of multiple inputs and multiple outputs, and find ways to improve efficiency. Especially in the study of the efficiency of commercial banks, more and more scholars have used the data envelopment analysis method to study the efficiency of banks, and also achieved a significant number of research results. For example, reference [5] first used the DEA method to measure the efficiency of commercial banks, which proved that the DEA model can give more accurate commercial bank efficiency. References [6] used the Malmquist index model to measure the total factor productivity of 269 credit unions in Australia. The results show that the total factor productivity of large-scale credit unions has increased under the level of technological progress. References [7] analyzed China's bank efficiency from 1997 to 2007. Overall, the total factor productivity of state-owned banks and joint-stock commercial banks is on the rise. References [8] used the Malmquist index model to measure the dynamic efficiency of 16 commercial banks in China. The study found that the efficiency of China's banking industry showed a trend of decreasing first and then rising. Therefore, this paper which based on the DEA-Malmquist method analyzes the operational efficiency of 13 Mongolian commercial banks between 2013 and 2017. 


\section{ECONOMETRIC MODEL}

Based on the global Malmquist exponential model proposed by Pastor and Lovell, the sum of all decision units in each period is used as the reference set of the evaluated unit, in other words, the same frontier is referenced in each period, so the calculation is a single Malmquist-Index,

$$
M_{g}\left(x^{t+1}, y^{t+1}, x^{t}, y^{t}\right)=\frac{D^{g}\left(x^{t+1}, y^{t+1}\right)}{D^{g}\left(x^{t}, y^{t}\right)} .
$$

According to the Malmquist exponential decomposition method proposed by reference [6], it can be decomposed into pure efficiency change, pure technology change and scale change factor:

$$
\begin{aligned}
M_{g}\left(x^{t+1}, y^{t+1}, x^{t}, y^{t},\right) & =\frac{D^{g}\left(x^{t+1}, y^{t+1}\right)}{D^{g}\left(x^{t}, y^{t}\right)} \\
& =P E C \times P T C \times S C H .
\end{aligned}
$$

However, when the Malmquist index is decomposed, the frontiers of each period are still used to measure the efficiency changes of the adjacent two periods.

$$
\begin{aligned}
& \mathrm{MI}=\mathrm{PTC} \times \mathrm{PEC} \times \mathrm{SCH} \\
& =\left[\frac{\mathrm{D}_{v}^{0}\left(x_{0}, y_{0}\right)}{\mathrm{D}_{v}^{1}\left(x_{0}, y_{0}\right)} \cdot \frac{\mathrm{D}_{v}^{0}\left(x_{1}, y_{1}\right)}{\mathrm{D}_{v}^{1}\left(x_{1}, y_{1}\right)}\right]^{1 / 2} \times \frac{\mathrm{D}_{v}^{1}\left(x_{1}, y_{1}\right)}{\mathrm{D}_{v}^{0}\left(x_{0}, y_{0}\right)} \\
& \times\left[\frac{\mathrm{SE}^{0}\left(x_{1}, y_{1}\right)}{\mathrm{SE}^{0}\left(x_{0}, y_{0}\right)} \cdot \frac{\mathrm{SE}^{1}\left(x_{1}, y_{1}\right)}{\mathrm{SE}^{1}\left(x_{0}, y_{0}\right)}\right]^{1 / 2} .
\end{aligned}
$$

Since the evaluated decision unit is already included in the reference set, the global reference Malmquist index does not have the problem of no feasible solution in the scale return change model, and all decision units use the same frontier, the global Malmquist index is transitive and multiplied.

\section{RESEARCH RESULT}

This section is based on the DEA-Malmquist method. According to the characteristics of commercial banks' input and output, this paper takes net interest expense, non-interest expense, net interest income and non-interest income as the main indicators of the study, excluding some sample banks with missing relevant indicators. In the end, 13 Mongolian commercial banks were selected as the research objects, and the total set of the 13 Mongolian commercial banks in 2013-2017 was used as a reference set to measure the change of total factor productivity between 2013 and 2017.

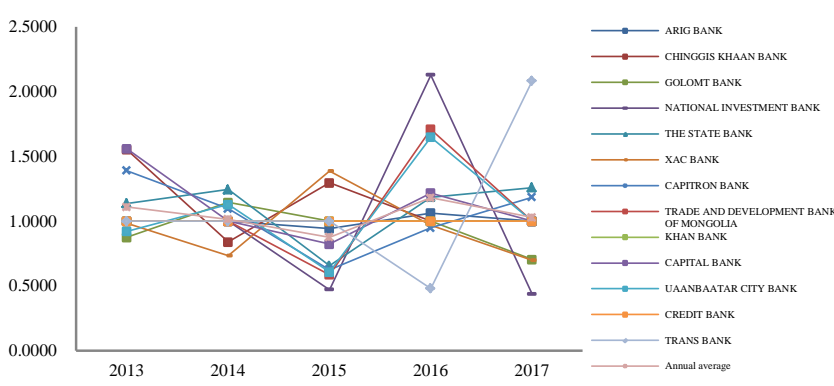

Fig. 1. Scale Change Factor(SCH)
Among the 13 Mongolian commercial banks, only Golomt Bank and Xac Bank have a mean change factor of less than 1 in the scale change factor (SCH) column, indicating that the scale efficiency of the two banks has declined in five years, so these Banks need to properly adjust the bank scale, improve the company's management system to improve the scale efficiency; Khan Bank And Xac Bank's scale change factor is 1, indicating that the scale efficiency of the two commercial banks in the five years has not changed much. The average value of the scale change factors of the other nine commercial banks is greater than 1, indicating that the scale efficiency of the five years is increasing. Chinggis Khaan Bank had the best change in size of 13 commercial banks, at 1.1374, and Golomt Bank had the worst change in scale, at 0.9442 .

From Fig. 1, we can see the scale change factor (SCH) of 13 Mongolian commercial banks in 2013-2017. In general, Mongolian commercial banks have two states in terms of scale change; one is to ignore the scale change. The role of bank's total factor productivity keeps the scale constant throughout the year, leading to a backward level in the banking process and affecting the bank's operating efficiency. The other is to pay too much attention to the impact of scale on efficiency and blindly expand the scale, resulting in scale inefficiency. For banks that despise scale changes, they need to change their existing scales, pay attention to their own scale changes, and small-scale banks should appropriately expand their scale. Large-scale banks need to appropriately improve the efficiency of other factors, and match according to the resources of banks. Reasonable resources cannot be blindly pursued on a large scale.

Among the 13 commercial banks, the pure efficiency changes of National Investment Bank and Capital Bank are greater than 1 , indicating that the pure efficiency of the two banks has generally increased in the past five years. While the other banks' pure efficiency change value is less than 1 , it is obviously that these banks need to optimize the management structure and adjust the management methods to change the status quo.
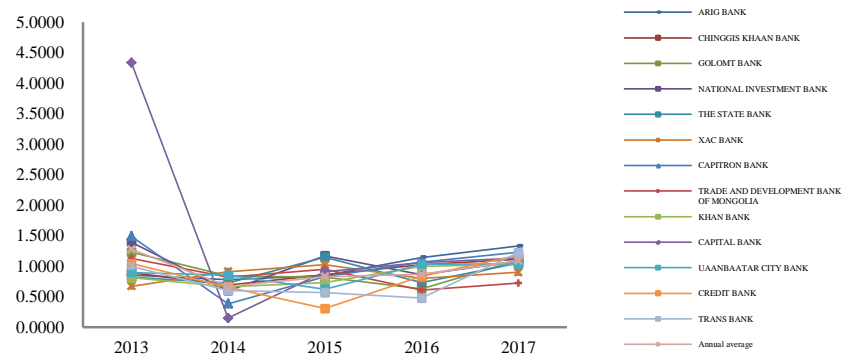

Fig. 2. Pure Efficiency Change(PEC)

Two of the 13 Mongolian commercial banks have a pure efficiency change greater than 1, while the remaining 11 banks have pure efficiencies of less than 1 , indicating that most banks have not improved their efficiency over the past five years and are in an ineffective state. From the perspective of the annual average of commercial banks, the pure efficiency change of commercial banks is generally rising. From Fig. 2, we can more clearly see the situation of pure efficiency change (PEC) of 13 Mongolian commercial banks in 2013-2017. Although 
the value of pure efficiency changes of 13 commercial banks has increased in 5 years, due to the increase It is greater than the degree of decline, so it generally shows an upward trend.

In the column of pure technology change (PTC), it can be seen that the pure technology change values of Xac Bank, Trade and Development Bank Of Mongolia, Credit Bank And Trans Bank 4 commercial banks are greater than 1, indicating that the pure technology change of the 4 bank is on the rise, while the pure technical changes of the other nine commercial banks are less than 1 , so these banks need to improve management and optimize business technology.

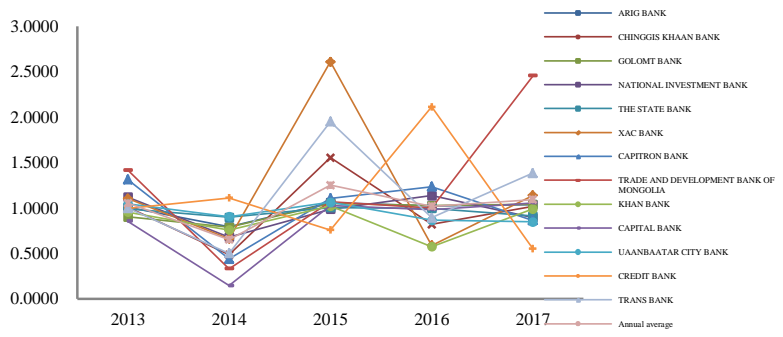

Fig. 3. Pure Technology Change(PTC)

Fig. 3 shows the pure technology changes of 13 Mongolian commercial banks in 2013-2017. The annual average value of pure technology changes reached a minimum in 2014, at 0.654 . It is shown that the financial crisis of 2014 for the Mongolian Commercial Bank caused harmful impact. In 2015, the value of pure technology has increased and reached the maximum in five years, at 1.251. It is obviously that the Mongolian banking industry has responded correctly to the financial crisis and promoted technological progress. Overall, the Mongolian commercial bank is in a state of technological progress for five years.

It can be seen from the Fig. 4 that the trend of the Malmquist index (MI) of 13 Mongolian commercial banks in 2013-2017 is basically consistent with the trend of pure efficiency change (PEC), and the scale change factor (SCH) in the five years is generally declining. Trends of the pure technology change (PTC) are generally on the rise, indicating that the growth of total factor productivity of Mongolian commercial banks is brought about by technological advancement.

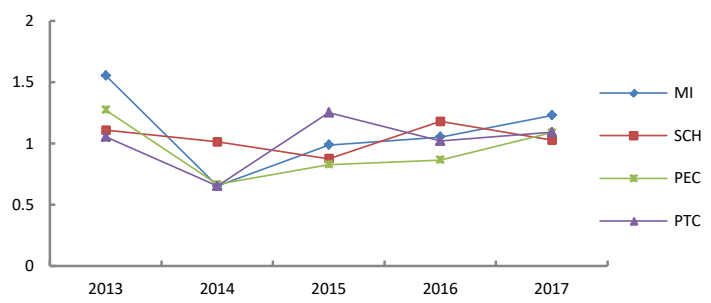

Fig. 4. Malmquist index decomposition factor changes

In general, during the period of 2013-2017, the change in total factor productivity of the sample banks studied in this paper is not stable. Therefore, in the future optimization process, commercial banks should pay more attention to the coordination of these two aspects. Only in this way can the total factor productivity be improved and more profits can be created for the banks.

\section{CONCLUSION}

Through the research, the following conclusions are drawn: (1) Firstly, the financial crisis encountered by Mongolia in 2014 has a great impact on Mongolian commercial banks, making the total factor productivity, pure efficiency change and pureness of Mongolian commercial banks in 2014. Both technological changes and scale change factors are at the lowest point in five years; (2) Pure Efficiency Changes and Pure Technology Changes are generally on the rise, and the growth of total factor productivity is brought about by technological advancement; (3) Mongolian bank system has two states in terms of scale change. One is to ignore the effect of scale change on the total factor productivity of banks. The scale remains unchanged throughout the year, affecting the efficiency of bank operations. The other is paying too much ion to the impact of scale on efficiency, resulting in no scale effectiveness.

This paper analyzes the total factor productivity of Mongolian commercial banks from three aspects: pure efficiency change, scale change factor and pure technology change. In fact, there are many factors affecting the operational efficiency of Mongolian commercial banks. Due to the lack of more detailed information, detailed analysis of various factors affecting Mongolian commercial banks has not been carried out, which needs further study.

\section{ACKNOWLEDGEMENT}

The research team is grateful to tutor and all students who took part in the study, as well as to the institution for supporting the scientific initiative and interest in its results.

\section{REFERENCES}

[1] Avid B, Purevsuren B, Born M, et al. "Pyrolysis and TG Analysis of Shivee Ovoo Coal from Mongolia”. Journal of Thermal Analysis \& Calorimetry, vol. 68, pp. 877-885, June 2002.

[2] Stennicke H R, Ostergaard H, Bayer R J, et al. "Generation and biochemical characterization of glycoPEGylated factor VIIa derivatives”. Thromb Haemost, vol. 100, pp. 920-928, May 2008.

[3] Sarantuya J, Nishi J, Wakimoto N, et al. "Typical enter aggregative Escherichia coli is the most prevalent path type among E. coli strains causing diarrhea in Mongolian children”. Journal of Clinical Microbiology, vol. 42, pp. 133-142, January 2004.

[4] Loar J, Haig A J, Yamakawa K S, et al. "Construct validation of the Language Independent Functional Evaluation versus the Barthel Index in a Mongolian community”. Disability \& Rehabilitation, vol. 33, pp. 319-325, April 2011.

[5] Sherman H D, Gold F. "Bank branch operating efficiency: Evaluation with Data Envelopment Analysis”. Management Science Letters, vol. 9, pp. 297-315, June 2014.

[6] Worthington A C. "Malmquist indices of productivity change in Australian financial services". Journal of International Financial Markets Institutions \& Money, vol. 9, pp. 303-320, August 1999

[7] Matthews K, Zhang N. "Bank productivity in China 1997-2007: Measurement and convergence”. China Economic Review, vol. 21, pp. 617-628, December 2010,

[8] Li Wei. "Research on the Efficiency and Influencing Factors of China's Commercial Banks-Based on Malmquist Index Analysis”. Journal of Southwest China Normal University(Natural Science), vol. 39, pp. 124-128, June 2014. (In Chinese) 